\title{
STUDENT, SOLDIER AND SENIOR SITES: VISIBLE AND ULTRAVIOLET RADIATION EFFECTS FIELD STUDY
}

\author{
P.R. HEBERT \& G. PEEK \\ Oklahoma State University, Oklahoma, Stillwater, OK, USA.
}

\begin{abstract}
Student, soldier, and senior sites utilize large amounts of visible optical radiation (VIS) to illuminate their premises. In housing across the United States, VIS accounts for almost one-fifth of energy consumption. Industry recommendations encourage the use of sustainability, but site lighting compliance is lacking. Over-illuminated sites waste electricity. Unsustainable lighting may also result in light pollution and 'light trespass'. These conditions may disrupt body clocks and cause human health problems. Invisible ultraviolet (UV) radiation, a component of optical radiation, is also associated with health risks. University researchers in the current study examine artificial VIS and UV radiation at 10 housing sites. The researchers led undergraduate students in night-time field studies to measure and document existing electric lighting. They used four tools to assess VIS, UV radiation, and sky quality in the field. VIS from various electric light sources was found. Some of light levels exceeded industry standards. Student and senior housing sites utilized shortlived and low efficacy light sources destined for landfills. Researchers found evidence of light pollution and light trespass. Sky quality was determined to be less than ideal. UV radiation had negligible effects. The quantified environmental effects of non-sustainable lighting sources included wasted light, light pollution, and light trespass.
\end{abstract}

Keywords: Environmental impact, housing, lighting, pollution, sustainability.

1 BACKGROUND

'Student, Soldier and Senior Sites: Visible and UV Radiation Effects Field Study' represents an expanded version of the presentation from the 2011 Fifth International Conference on Sustainable Development and Planning [1]. In the United States, interest in artificial visual optical radiation (VIS) is increasing among researchers and the public. Consumers utilize VIS to illuminate living spaces and the near environment. This energy use yields benefits, including those related to comfort, safety, and security. However, use of artificial optical radiation yields negative externalities, which may have adverse effects on both the environment and wellbeing. Inefficient lighting wastes energy, creating direct environmental impacts. Inefficient lighting can also create light pollution and trespass, affecting both human and animal wellbeing. Reducing illumination overages may reduce wasted energy and have positive impacts on well-being.

\section{PURPOSE}

The purpose of 'Student, Soldier and Senior Sites: Visible and UV Radiation Effects Field Study' was to examine the outdoor lighting conditions at three types of housing sites. These sites included student housing maintained by Universities, solider housing located both on-base and off-base, and senior housing maintained by a continuing care retirement facility (CCRC). The sample consists of 10 housing sites. Faculty and students participated in research teams to: (1) measure artificial optical radiation; (2) identify non-sustainable light sources at housing sites; and (3) determine if artificial optical radiation was found on housing units' fenestration. 


\section{LITERATURE REVIEW}

3.1 Basic definitions: artificial optical radiation, light pollution, and light trespass

What is artificial optical radiation? First, the term artificial refers to that which is not natural. For example, the electric light produced by an ordinary desk lamp is artificial. Eurofound, an agency of the European Union, defines optical radiation as 'any electromagnetic radiation in the wavelength range between $100 \mathrm{~nm}$ and $1 \mathrm{~mm}$ '. The ISE Light and Human Health committee states that the term optical radiation 'should be used to describe the portion of the electromagnetic spectrum spanning ultraviolet, visible, and infrared radiation that stimulates ... biological responses' [2]. These biological responses include but are not limited to circadian, neuroendocrine, and neurobehavioral responses.

For this study, researchers are concerned with artificial VIS produced by exterior lighting sources used at night in residential settings. This commonly includes building mounted security lighting, building floodlighting, pathway and street lights, porch lights, lighting from adjacent buildings, etc. Exterior fixtures commonly use incandescent, fluorescent, metal halide, and high pressure lamps. Less commonly, neon and light emitting diodes (LEDs) have been utilized.

Artificial VIS in housing and residential context is useful. Although it has long been understood that artificial optical radiation has both health benefits and risks [3], humans have increasingly illuminated their world [4]. Some have identified aesthetic, safety, and security issues as reasons for illumination. VIS allows us to conduct activities of daily living at night, including, eating, reading, walking, and driving, to name a few. Without artificial optical radiation, we would not be able to see at night. Our vision would be severely impaired in today's fast-paced environment without artificial VIS.

Although optical radiation is often associated with positive outcomes, negative aspects are also associated. The UV radiation component of artificial optical radiation may also potentially be harmful in a housing and residential context. This study is also concerned with light pollution and light trespass. Light pollution is defined as 'the scattering of electric light into the atmosphere, usually caused by luminous flux above the horizontal'; light trespass is defined as 'light that strays from its intended purpose, causing visual annoyance' [5]. Per Winchip [6], light trespass may be an externality associated with light pollution. Figure 1 illustrates that light trespass may be associated with light pollution.

\subsection{Concerns about lighting in residential settings}

Artificial light from unshielded and poorly located sources may enter buildings through fenestration. This light trespass may disturb slumber, disrupt circadian rhythms, or otherwise

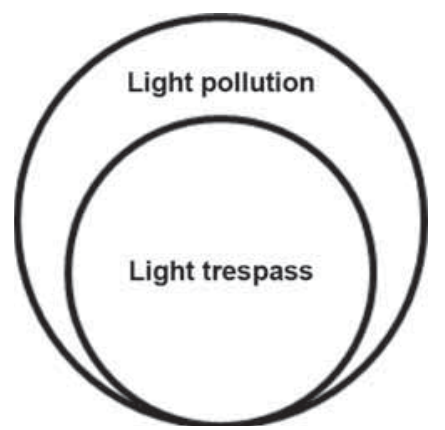

Figure 1: Stacked Venn diagram relating light trespass to light pollution. 
negatively influence health. The Illuminating Engineering Society of North America (IESNA) - an organization that publishes lighting-related research, as well as recommend levels of VIS for particular visual tasks - recently emphasized the profound effect of light on human health and the importance of studying dark/light cycles [3]. Although the exact light levels required to impact human circadian rhythms are as yet unknown, several studies involving light and circadian rhythm were found [7-10]. Boyce [11] and Figueiro et al. [12], among others, have called for the continued study of light and circadian rhythms. Figueiro et al. [12] expressed concern about the possible link between night-time exposure to artificial light and increased cancer risk.

Others perceive artificial VIS as a disruption of the natural dark/light cycle and a waste of energy. Rich and Longcore have written about the negative environmental effects of lighting, including those on various species [13]. In 2009, the American Medical Association (AMA) released a mandate supporting sustainable lighting, waste reduction, and light pollution reduction [14]. Additional researchers have studied non-visible light and its health implications [15-20].

\subsection{Contributions to previous literature}

Research precedence was found for the utilization of questionnaires to assess the awareness, knowledge, experience, or intentions of participants regarding sustainable lighting [21]. Also, several studies were found regarding the utilization of energy efficient (higher efficacy and longer lived) lighting sources, LEDs or Compact Fluorescent Lighting (CFLs), outside of the United States [22-26]. Consumers' attitudes toward LEDs, CFLs, and incandescent were examined by Stall-Meadows and Hebert [27] in empirical field research set in museums; this study also utilized student researchers. Other lighting field studies were found [28-30]. Programs such as ENERGY STAR [31] encourage energy-saving lighting, and others have gathered topical market research [32]. Consortium for Energy Efficiency (CEE) cited inadequate consumer education as a barrier to the adoption of CFLs [33]. No previous studies quantifying optical radiation at housing sites or involving students in housing field study data collection were found.

The current exploratory study utilized concepts from Sherri Arnstein's classic theoretical work, 'A Ladder of Citizen Participation' [34]. Arnstein encouraged 'citizen' stakeholders to facilitate decision-making processes made by societies, including those relative to planning and design. She devised an eight-rung ladder model, divided into three groups of rungs, ascending toward more participatory practices. The lowest group that she identified as 'nonparticipation' included 'manipulation' and 'therapy'. The middle group was labeled 'tokenism'. Tokenism included 'informing', 'consultation', and 'placation'. She called the top group 'citizen power', which included 'partnership', 'delegated power', and the top rung, 'citizen control'. By involving student stakeholders, the current study endeavors to fill a gap in the existing literature regarding the impacts of non-sustainable artificial optical radiation. According to Attardi, 'to create a future of growth and sustainability should be our message ... Educating the general public on lighting is ... a very good idea' [35]. He proposed a model to explain consumer behavior relative to sustainable lighting. He claimed that awareness of new lighting technologies led to acceptance, which led to preference [35]. In the current exploratory study, both Arnstein's and Attardi's theoretical works were applied by engaging students in an investigation of the effects of optical radiation at University housing sites. 


\section{METHODOLOGY}

\subsection{Housing types used in study}

Students. This study examines existing student housing sites in University settings. The Universities are located in two Midwestern states and are large with at least 20,000 undergraduate students at each. The Universities provide a number of housing options for students, as the schools are live-in as opposed to commuter. The University-owned and maintained student housing mainly takes the form of multifamily, dwelling with housing units clustered around green space areas.

Soldiers. This study examines existing soldier housing sites. The military provides several housing options for soldiers. Soldiers may live in on-base housing, which typically takes the form of barracks or multifamily. Soldiers may also live in off-base housing located in the community. Here, soldiers have the option to rent or purchase housing. These homes can include multifamily apartments or single-family houses.

Seniors. This study examines existing senior housing sites in a continuing care retirement center (CCRC). According to Medicare, the US government is charged with providing health insurance to elders aged 65 and older and other limited populations [36]. CCRCs are extended care facilities that offer a range of housing types and healthcare options. In a single CCRC, there may be a combination of single-family housing, multifamily apartments, and a facility dedicated to nursing home care. Many times, residents begin living more independently with lower levels of care. As health conditions begin to decline, residents will move to higher levels of care culminating in the nursing home. CCRCs will typically charge a large entry fee, coupled with monthly payments [37].

Table 1 provides basic information about the housing sites used in the current study. Sites were selected via convenience sampling. The 10 chosen sites, located in three cities in two states in the Midwestern United States, represented different aspects of housing building types (single-family homes, single soldier housing, duplexes, congregate housing, etc.) and served different populations. All sites were within several hours driving distance of the researchers' home institutions. These site choices kept travel distance, fossil fuel expenditures, and travel time relatively low for the field studies.

Table 1: Housing sites used in study.

\begin{tabular}{lccc}
\hline Site & $\begin{array}{c}\text { Location: City (designated by } \\
\text { symbol) }\end{array}$ & Location: State $\mathrm{x}$ or y & Site type (housing) \\
\hline A & $\bullet$ & $\mathrm{x}$ & student \\
B & $\bullet$ & $\mathrm{x}$ & student \\
C & $\bullet$ & $\mathrm{x}$ & student \\
D & $\bullet$ & $\mathrm{x}$ & student \\
E & $\diamond$ & $\mathrm{x}$ & student \\
F & $\mathbf{\square}$ & $\mathrm{y}$ & senior \\
G & $\square$ & y & soldier \\
H & $\square$ & y & soldier \\
I & $\square$ & y & soldier \\
J & $\square$ & & soldier \\
\hline
\end{tabular}

Note: The term student refers to University student. 
Administrators of some of the sites, or their parent organizations, had indicated a commitment to sustainability on their website or in other literature.

Prior to beginning the field study work, written permission to access the chosen sites and to take site photographs was requested from and granted by all of the 10 housing sites' administrators. Site administrators were initially contacted via email and telephone. Researchers also met with senior and soldier sites' administrators prior to acquiring final permissions to proceed. The senior and soldier sites were also gated and access to outsiders was restricted. Further, the soldier sites were located on a US military installation and the sites were protected by armed guards and vehicle checkpoints. Upon arrival at the gates of the military installation, researchers were required to present personal identification, a letter of invitation, and proof of automobile insurance in order to enter. Further, the researchers were asked to step out of their vehicle, which was thoroughly searched for potentially dangerous materials, such as firearms, explosive devices, and other prohibited items, prior to site entry. Paperwork review and vehicle search were common procedures followed for nonmilitary personnel and vehicle admittance. Since the researchers visited each site several times to acquire site plans, meet with site administrators, tour facilities, select specific buildings for measurements, and perform measurements and photography, these military checkpoint procedures were completed multiple times during the study period. During one site survey at the military installation at night, researchers were approached by resident soldiers who queried them as to their purpose.

\subsection{Data collection}

In the current study, three research hypotheses were proposed and tested:

$H_{1}$ : Artificial VIS at housing sites will exceed recommendations.

$\mathrm{H}_{2}$ : Non-sustainable light sources will be identified at housing sites.

$H_{3}$ : Artificial VIS and UV radiation will be found on housing units'fenestration.

During three months of the research period, from October 4 to December 21, 2010, 66 undergraduate university students, 4 graduate students, 3 faculty members, and 1 community member participated in one or more of 10 site visits. The weather and moon phases for each of the sites during the study period were obtained from official sources.

Using IESNA nomenclature, each site was classified as having either 'bright surroundings' or 'dark surroundings' [38], based on the ambient visual illumination proximal to each housing site. The current researchers also classified the sites' predominant vertical surfaces' reflectance values using IESNA terms: 'light', 'medium light', 'medium dark', or 'dark' [38]. To determine reflectances, the researchers compared building surfaces to paint chips and corresponding light reflectance values (LRVs) published in paint manufacturers' fan decks (Imperial Chemical Industries Paints and PPG Pittsburgh Paints). Through visual inspection, the researchers determined which paint chips most closely matched the field sites' exterior buildings' surfaces. The corresponding LRVs were noted. The two digits of the LRV corresponded to the percentage of light reflected. A surface with an LRV of 75 reflected $75 \%$ of the light falling upon it. For the purposes of this study, 'light' surfaces were those with an LRV of 75-99, 'medium light' surfaces were 50-74, 'medium dark' surfaces were 25-49, and 'dark' surfaces were 24 or less. Additionally, the research team utilized spectral distribution identification cards with diffraction gratings to distinguish observed light sources as incandescent, fluorescent, mercury, metal halide, sodium, or neon. Figure 2 shows field use of diffraction gratings.

At each site, the researchers field-selected ground floor housing units with windows. The researchers examined the sites' existing lighting fixtures, noted their overall styles, and determined if they were 'cutoff' or 'non-cutoff' through visual inspection and comparison to industry standards. They 


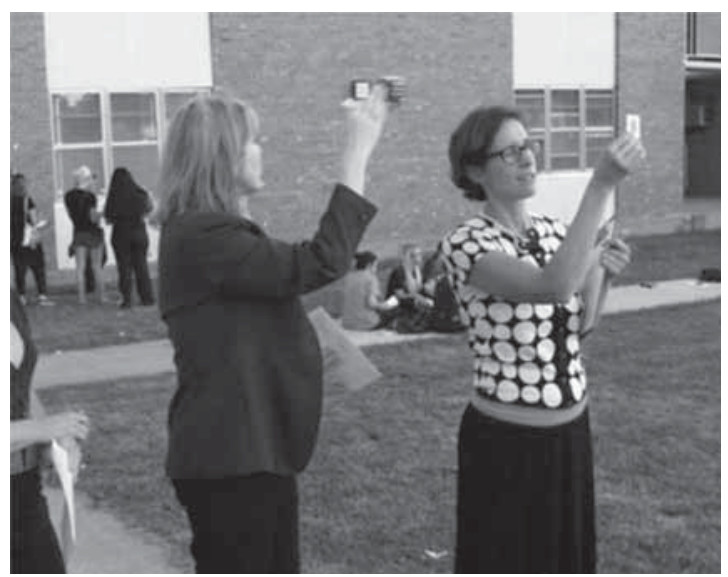

Figure 2: Field use of diffraction gratings.

used masking tape to prepare temporary measurement grids on horizontal surfaces (on-grade landscape and paving adjacent to housing units) and vertical surfaces (housing units' exterior walls, and windows).

Providing the temporary measurement grid facilitated the measurement of VIS and UV radiation at regular intervals. Selected intervals for measurements varied, as per industry practices. Measurements on the vertical faces of buildings were made approximately 2'-0" ( $0.61 \mathrm{~m})$ on center. On-grade measurements on horizontal surfaces surrounding buildings were taken at intervals ranging from 3'-0" $(0.91 \mathrm{~m})$ to 20 '-0" $(6.10 \mathrm{~m})$ on center, corresponding to the approximate heights of the light centers of exterior lighting sources in the area including: bollards, building mounted floodlights, and pole mounted fixtures.

Beginning at $19.30 \mathrm{~h}$ on seven separate evenings, researchers examined and measured the artificial VIS and UV radiation falling on vertical and horizontal planes. This information was recorded on field data sheets, plans, and sketches. The research team measured VIS in footcandles (fc) and lux (lx) with a GTE Sylvania DS-2000 $\mathrm{m}$ at selected housing units. Figure 3 shows field measurements.

At these identical locations, UV radiation was also measured in microwatts $/ \mathrm{cm}^{2}$ with a Mannix UV-340 m, which measured UVA and UVB in the 290-390 nm range. Overall sky quality measurements were taken at each site, determined in magnitudes per square arcsecond, using a Unihedron Sky Quality meter, SQM-L. A higher sky quality reading indicated a lower level of light pollution. For example, a reading of 21 would indicate a very dark sky, while a reading of 16 would indicate a light polluted sky [39]. Researchers also documented sites and field research activities with digital cameras. From November 2010 through February 2012, researchers transferred data from field sheets, coded the data, compared field measurements to IESNA and International Dark-Sky Association recommendations, and analyzed findings.

\section{RESULTS}

About $50 \%$ of the sites, Sites A, B, C, D, and F, experienced clear skies during field study visits. One of the sites, Site E, was 'mostly cloudy'. Four of the sites, Sites F, H, I and J were classified as 'cloudy'. The temperatures ranged from a low of $29^{\circ} \mathrm{F}\left(-1.67^{\circ} \mathrm{C}\right)$ at Sites F, H, I, and J to a high of $73^{\circ} \mathrm{F}\left(23^{\circ} \mathrm{C}\right)$ at Site $\mathrm{C}$. None of the sites experienced any precipitation during the field visits. The moon phases varied from waning crescent to full moon. At the student housing sites, sky quality 


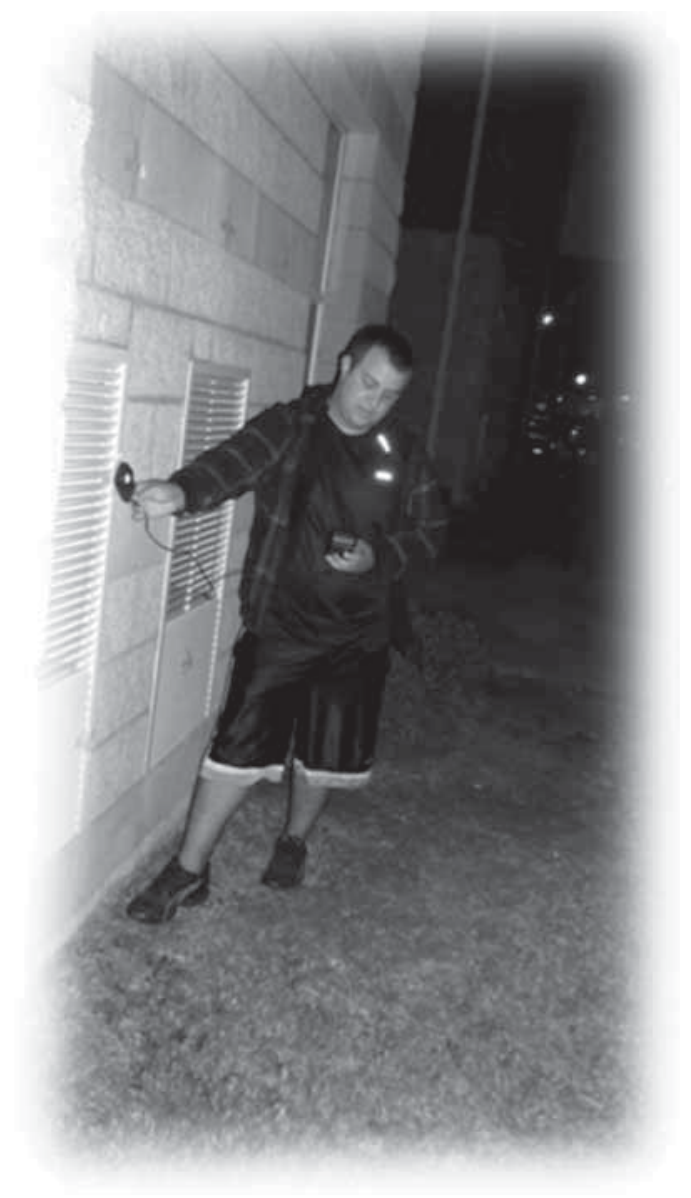

Figure 3: Field measuring with light meter.

measures were variable and ranged from a minimum of 10.80 mags/arcsecond ${ }^{2}$ at Site $\mathrm{D}$ to a maximum of 18.00 mags/arcsecond ${ }^{2}$ at Site C. The mean of the student housing sites measurements was 15.02. Therefore, sky quality was categorized as poor to fair, with evidence of light pollution found at all five student housing sites. At the senior housing sites, light pollution was also evident with measurements steady at $17.13 \mathrm{mags} / \mathrm{arcsecond}^{2}$. At the soldier housing sites, measurements ranged from 15.80 to 18.29 mags/arcsecond ${ }^{2}$. The majority of the readings at the soldier housing sites $(n=$ 12, 80\%) fell between 17.13 and 18.29 mags/arcsecond ${ }^{2}$. The darkest skies were recorded at the soldier housing sites. The mean of the soldier housing sites was $17.31 \mathrm{mags} / \mathrm{arcsecond}^{2}$, the highest mean found across housing types. Exterior lighting fixtures were categorized by the researchers through visual inspection, as seen in Fig. 3.

Table 2 provides information about housing site conditions and light fixtures. Only Sites C, E, and $\mathrm{J}$ utilized cutoff fixtures exclusively, as shown.

Table 3 provides information about light source identification. A total of 167 spectral distribution identifications were made by the researchers. The light source most often identified across all sites was fluorescent $(n=56,33.53 \%)$. Fluorescent was identified at most $(n=8,80 \%)$ of the studied sites 
Table 2: Housing site conditions and light fixtures.

\begin{tabular}{|c|c|c|c|c|c|c|c|c|c|}
\hline \multirow[b]{2}{*}{$\begin{array}{l}\text { Site } \\
\text { label }\end{array}$} & \multirow[b]{2}{*}{$\begin{array}{c}\text { Housing } \\
\text { type }\end{array}$} & \multicolumn{3}{|c|}{$\begin{array}{l}\text { Sky quality reading } \\
\text { (mags/arcsecond2) }\end{array}$} & \multirow[b]{2}{*}{ Cutoff } & \multicolumn{3}{|c|}{ Weather } & \multirow[b]{2}{*}{ Moon phase } \\
\hline & & Min & Max & Mean & & $\begin{array}{l}\text { Cloud } \\
\text { cover }\end{array}$ & $\begin{array}{l}\text { Precipi- } \\
\text { tation }\end{array}$ & $\begin{array}{l}\text { Temp } \\
{ }^{\circ} \mathrm{F}\left({ }^{\circ} \mathrm{C}\right)\end{array}$ & \\
\hline A & student & 15.4 & 17.5 & 16.3 & No & Clear & 0 & 65 (18.33) & $\begin{array}{l}\text { Waning } \\
\text { crescent } 14 \%\end{array}$ \\
\hline B & student & 15.6 & 16.1 & 15.7 & No & Clear & 0 & $69(20.56)$ & $\begin{array}{l}\text { Waning } \\
\text { crescent 6\% }\end{array}$ \\
\hline $\mathrm{C}$ & student & 16.1 & 18 & 16.4 & Yes & Clear & 0 & $73(22.78)$ & $\begin{array}{l}\text { Waning } \\
\text { crescent 2\% }\end{array}$ \\
\hline $\mathrm{D}$ & student & 10.8 & 10.8 & 10.8 & No & Clear & 0 & 55 (12.78) & $\begin{array}{l}\text { Waning } \\
\text { Gibbous } 87 \%\end{array}$ \\
\hline $\mathrm{E}$ & student & 16.1 & 16.3 & 16.2 & Yes & $\begin{array}{l}\text { Mostly } \\
\text { cloudy }\end{array}$ & 0 & $45(7.22)$ & Full $100 \%$ \\
\hline $\mathrm{F}$ & senior & 17.13 & 17.13 & 17.13 & No & Clear & 0 & $56(13.33)$ & $\begin{array}{l}\text { Waxing } \\
\text { Gibbous 96\% }\end{array}$ \\
\hline G & soldier & 18.29 & 18.29 & 18.29 & No & Cloudy & 0 & $29(-1.67)$ & Full $100 \%$ \\
\hline $\mathrm{H}$ & soldier & 17.69 & 17.69 & 17.69 & No & Cloudy & 0 & $29(-1.67)$ & Full $100 \%$ \\
\hline I & soldier & 17.44 & 17.44 & 17.44 & No & Cloudy & 0 & $29(-1.67)$ & Full $100 \%$ \\
\hline $\mathrm{J}$ & soldier & 15.8 & 15.8 & 15.8 & Yes & Cloudy & 0 & $29(-1.67)$ & Full $100 \%$ \\
\hline
\end{tabular}

with the exception of Site D, the senior housing site and Site J, a soldier housing site. The second most identified light source was incandescent $(n=41,24.55 \%)$. Incandescent was found at all six of the student housing sites, which were located on two different campuses. Incandescent was also found at the senior housing site. Metal halide was the third most identified light source $(n=34$, $20.36 \%)$. Metal halide sources were found at all four of the soldier housing sites. The least identified light sources included: sodium ( $n=17,10.18 \%)$, mercury $(n=12,7.19 \%)$, and neon $(n=7,4.19 \%)$, as shown in Table 3.

\subsection{Comparison of field readings and industry standards}

The researchers determined that artificial VIS was evident at all of the sites studied. The measured light levels ranged from a minimum of 0.0 horizontal $\mathrm{fc}(0.0 \mathrm{~lx})$ to a maximum of 6.7 horizontal $\mathrm{fc}$ (72.5 lx); and a minimum of 0.1 vertical fc $(1.1 \mathrm{~lx})$ to a maximum of 4.9 vertical fc $(52.7 \mathrm{~lx})$. Some measureable light levels were found on or near windows of housing units, including $1.3 \mathrm{fc}(14 \mathrm{~lx})$ at Site E. The vast majority of the housing sites $(n=9,90 \%)$ were classified as having 'dark surroundings' (Sites A, C, D, E, F, G, H, and I). Via visual inspection, only Site B was determined to have 'bright surroundings'. The sites' exterior building surfaces' reflectance values were examined and the vast majority of sites, Sites A, B, C, D, E, F, G, H, and I ( $n=9,90 \%)$, were classified as 'dark' 
Table 3: Lighting source identification.

\begin{tabular}{|c|c|c|c|c|c|c|c|c|c|c|c|c|c|}
\hline \multirow{2}{*}{$\begin{array}{l}\text { Site } \\
\text { label }\end{array}$} & \multirow{2}{*}{$\begin{array}{l}\text { Housing } \\
\text { type }\end{array}$} & \multicolumn{2}{|c|}{ Incandescent } & \multicolumn{2}{|c|}{ Fluorescent } & \multicolumn{2}{|c|}{ Mercury } & \multicolumn{2}{|c|}{ Metal halide } & \multicolumn{2}{|c|}{ Sodium } & \multicolumn{2}{|c|}{ Neon } \\
\hline & & \# & $\%$ & \# & $\%$ & \# & $\%$ & \# & $\%$ & \# & $\%$ & \# & $\%$ \\
\hline A & student & 15 & 36.59 & 20 & 35.71 & 4 & 33.33 & 2 & 5.88 & 12 & 70.59 & 6 & 85.71 \\
\hline $\mathrm{B}$ & student & 2 & 4.88 & 8 & 14.29 & 0 & 0.0 & 4 & 11.76 & 2 & 11.76 & 1 & 14.29 \\
\hline $\mathrm{C}$ & student & 19 & 46.34 & 21 & 37.5 & 8 & 66.67 & 19 & 55.88 & 1 & 5.88 & 0 & 0.0 \\
\hline $\mathrm{D}$ & student & 2 & 4.88 & 0 & 0.0 & 0 & 0.0 & 0 & 0.0 & 0 & 0.0 & 0 & 0.0 \\
\hline $\mathrm{E}$ & student & 1 & 2.44 & 1 & 1.79 & 0 & 0.0 & 1 & 2.94 & 0 & 0.0 & 0 & 0.0 \\
\hline $\mathrm{F}$ & senior & 2 & 4.87 & 0 & 0.0 & 0 & 0.0 & 0 & 0.0 & 0 & 0.0 & 0 & 0.0 \\
\hline G & soldier & 0 & 0.0 & 2 & 3.57 & 0 & 0.0 & 2 & 5.88 & 0 & 0.0 & 0 & 0.0 \\
\hline $\mathrm{H}$ & soldier & 0 & 0.0 & 2 & 3.57 & 0 & 0.0 & 2 & 5.88 & 0 & 0.0 & 0 & 0.0 \\
\hline I & soldier & 0 & 0.0 & 2 & 3.57 & 0 & 0.0 & 2 & 5.88 & 2 & 11.76 & 0 & 0.0 \\
\hline $\mathrm{J}$ & soldier & 0 & 0.0 & 0 & 0.0 & 0 & 0.0 & 2 & 5.88 & 0 & 0.0 & 0 & 0.0 \\
\hline Total & & 41 & 100 & 56 & 100 & 12 & 100 & 34 & 100 & 17 & 100 & 7 & 100 \\
\hline
\end{tabular}

with corresponding LRVs of 15, 16, 17, 16, 19, 19, 8, 17, and 17 as shown in Table 4. Only one site, Site I $(n=1,10 \%)$, was considered to have 'medium dark' reflectance value with corresponding LRV of 29.

For 'floodlighting buildings and monuments' with dark surroundings and dark surfaces, as in Sites $A, C, D, E, F, G$, and $H$, the IESNA recommends an average of 5 vertical fc (50 lx). For bright surroundings and dark surfaces, as in Site B, the corresponding value is: $15 \mathrm{fc}(150 \mathrm{~lx})$ [38]. For dark surroundings and medium dark surfaces, as in Site I, the corresponding value is $4 \mathrm{fc}$ (401x). All sites' corresponding means fell below these recommendations, refer to Fig. 4. However, the maximum reading at one site, Site I, was found to be just below the recommended $5 \mathrm{fc}$ level, at $4.9 \mathrm{fc}$ (52.7 lx).

For 'security', the recommended average vertical illumination on building exteriors is 0.5 to $2.0 \mathrm{fc}$ (5 to $201 \mathrm{x}$ ) [38]. The vertical mean measurements on the walls and windows of less than two-thirds of the sites $(n=6,60 \%)$ fell within this range: A $(0.9 \mathrm{fc}, 9.7 \mathrm{~lx}), \mathrm{B}(1.3 \mathrm{fc}, 13.9 \mathrm{~lx}), \mathrm{C}(1.1 \mathrm{fc}, 11.8 \mathrm{~lx})$, $\mathrm{E}(1.2 \mathrm{fc}, 19.4 \mathrm{~lx}), \mathrm{F}(1.1 \mathrm{fc}, 11.8 \mathrm{~lx}), \mathrm{I}(1.3 \mathrm{fc}, 13.99 \mathrm{~lx})$, and $\mathrm{J}(0.7 \mathrm{fc}, 6.9 \mathrm{~lx})$. The vertical means for less than one-third of the sites, Sites D (0.1 fc, $1.1 \mathrm{~lx}), \mathrm{G}(0.1 \mathrm{fc}, 1.1 \mathrm{~lx})$, and $\mathrm{H}(0.4 \mathrm{fc}, 4.2 \mathrm{~lx})$, were found to be below these recommendations, Fig. 5. One site $(n=1,10 \%)$, Site I ( $3.4 \mathrm{fc}, 36.5 \mathrm{~lx})$, was found to exceed the recommended range.

For 'safety', IESNA publishes horizontal average VIS recommendations for building grounds. It addresses 'hazards requiring visual detection' which are classified as either 'slight' or 'high' [38]. Due to the lack of critical obstacles observed during field visits to building that surrounds across housing site types, researchers classified all sites' hazards in the current study as slight. Within the hazards category, IESNA also distinguishes between 'low' and 'high' normal activity levels. Based on the field-observed activity levels, the researchers classified all sites' activities as low. For 'slight hazards requiring visual detection' at 'low levels of normal activity', IESNA recommends $0.5 \mathrm{fc}$ horizontal (5.4 lx). Only the mean horizontal measurements taken at one of the sites, Site $\mathrm{H}$, were found to meet the recommendations for slight hazards and low normal activity ( $0.5 \mathrm{fc}, 5.5 \mathrm{~lx})$. The mean horizontal measurements at less than two-thirds of the sites $(n=6,60 \%)$, Sites A $(0.8 \mathrm{fc}, 8.6 \mathrm{~lx})$, 


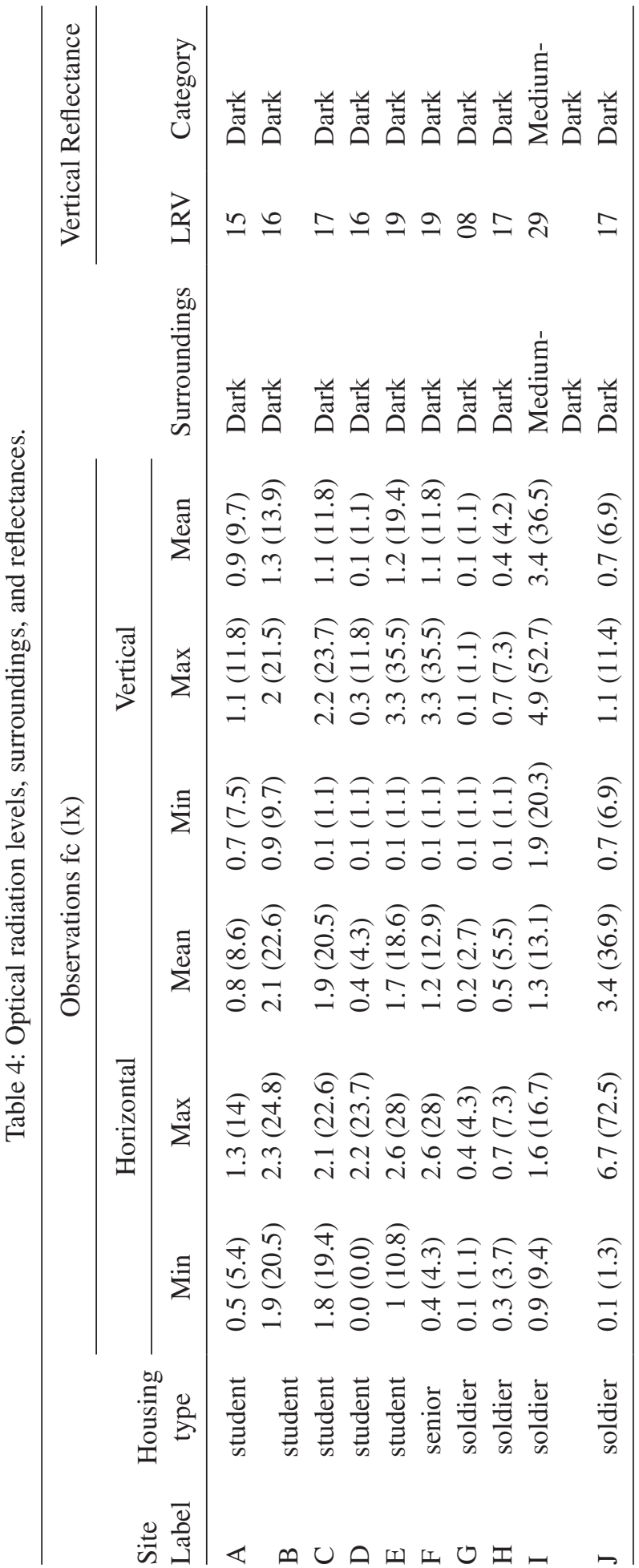




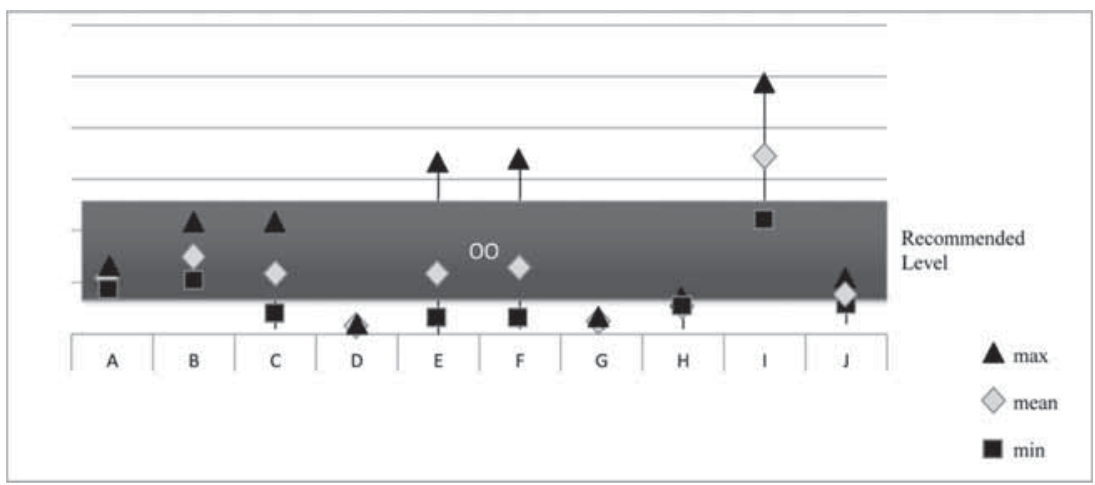

Figure 4: Security - Vertical light levels per site.

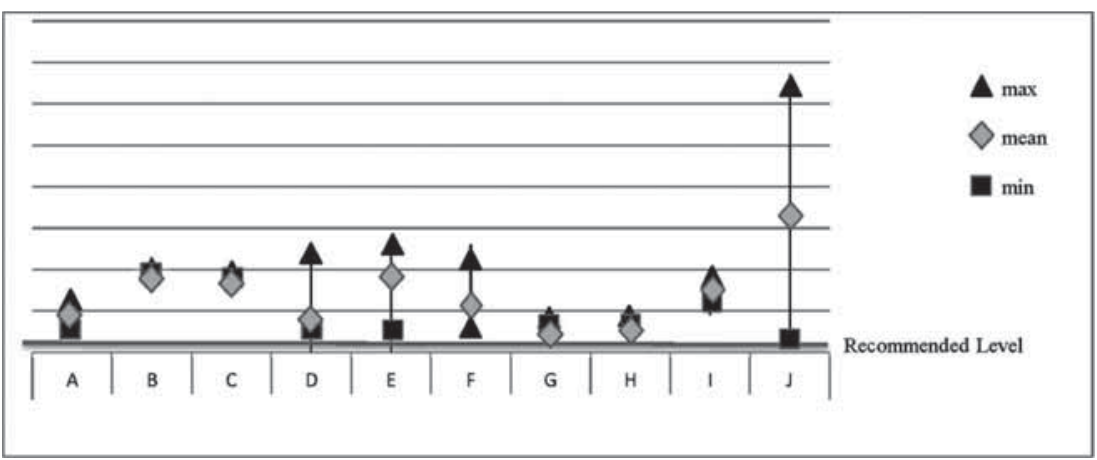

Figure 5: Safety - Horizontal light levels per site.

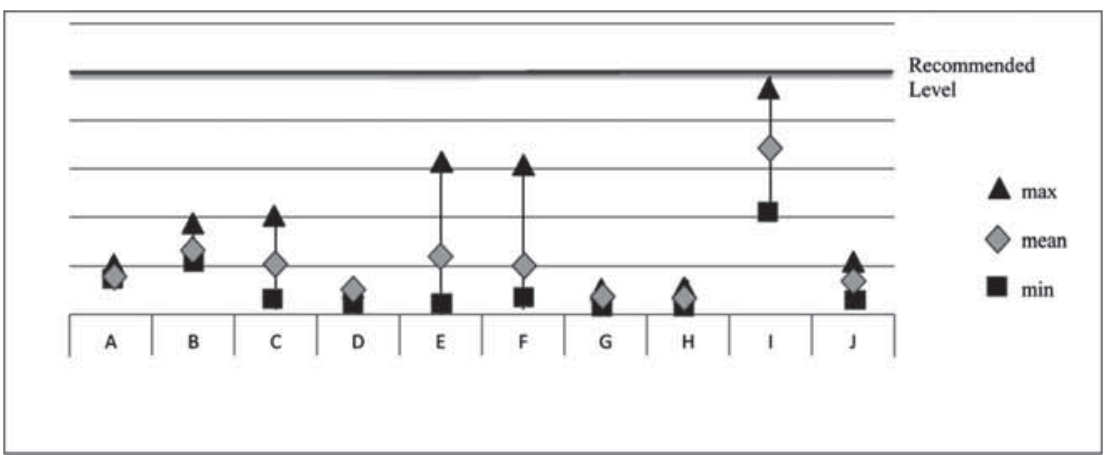

Figure 6: Floodlighting - Vertical light levels per site.

B (2.1 fc, 22.6 lx), C (1.9 fc, 20.5 lx), E (1.7 fc, 18.6 lx), F (1.2 fc, 12.9 lx ), and J (3.4 fc, 36.9 lx), exceeded these recommendations, while the mean at almost one-third $(n=3,30 \%)$ of the sites, Sites $\mathrm{D}(0.4 \mathrm{fc}, 4.3 \mathrm{~lx}), \mathrm{G}(0.2 \mathrm{fc}, 2.7 \mathrm{~lx})$, and I (1.3 fc, $13.1 \mathrm{~lx})$ fell below the recommended level, Fig. 6. UV radiation was also measured at regular intervals at the sites. All $(10,100 \%)$ sites' UV radiation measurements were negligible, 0 microwatts $/ \mathrm{cm}^{2}$. 


\section{LIMITATIONS}

The spectral distribution identification cards used in the field studies provided an incomplete offering of light source categories. The 'fluorescent' category did not allow for the differentiation between CFL and other types of fluorescent lighting. A LED category was not included on the cards. The cards have a copyright date of 1994, prior to the advent of increased LED source use in some exterior lighting applications in the United States. However, anecdotal evidence collected from site administrators and lighting experts, revealed that LEDs were not present in any of the sites in the current study. Another limitation was that the study sites were not randomly selected. Study sites were limited in their number and their geographic area, the age of the facilities was not taken into account in the current study. These facts decrease our ability to generalize from this study's findings. The research team included undergraduate students who had limited training in research methods.

\section{CONCLUSION AND DISCUSSION}

The purpose of 'Student, Soldier and Senior Sites: Visible and UV Radiation Effects Field Study' was to examine the outdoor lighting conditions at three types of housing sites. In total, this work engaged students in research efforts to examine existing artificial VIS and UV radiation at housing sites. It was concluded that this research successfully reached the participatory 'citizen power' tier of the theoretical model described by Arnstein's 'ladder of citizen participation'. Faculty and students worked together on teams to take measurements at three distinct housing types, that is, housing intended for university students, soldiers, and seniors. The research was motivated by three actions based on the three hypotheses, as follows. Measurements taken, given the action steps, partially or fully supported the three hypothesis.

\subsection{Hypothesis 1: artificial VIS levels at housing sites will exceed recommended levels}

Researchers partially accepted Hypothesis 1 given artificial VIS measurements. Light readings in situ revealed that many housing sites were illuminated to levels higher than industry recommendations. Sky quality across housing sites varied. Poor sky quality is considered unsustainable and often represents wasteful artificial lighting conditions onsite; the researchers suggest that the unshielded fixtures at some sites threw wasted light into the sky. However, moon phases may also have adversely affected overall sky quality readings, especially affecting Sites D, E, F, G, H, I, and J. These sites experienced $87 \%$ or more visible moon face during the study period.

The average visible light levels measured at some sites exceeded that recommended by the IESNA for safety. However, at some student housing sites, stakeholders may have created higher light levels in the cause of pedestrian safety. The non-cutoff pole fixtures, utilized at some of the sites across all three housing types, may have been an attempt to reinforce a nostalgic image. However, cut-off fixtures are more sustainable because they direct light where it is needed instead of skyward or into the bedroom windows of housing units. Stakeholders of student, soldier, and housing sites may wish to consider important externalities when developing plans for artificial optical radiation at housing sites.

\subsection{Hypothesis 2: non-sustainable light sources will be identified at housing sites}

Researchers accepted Hypothesis 2 light sources identified. The most common light source at all sites was fluorescents. Fluorescents are more sustainable relative to incandescents; fluorescents have higher efficacy and longer life than incandescents. However, fluorescents produce UV light. Fortunately, the envir-onmental impact of UV light at these sites was found to be negligible. This may be due to the lenses fitted to the fluorescents, which were apparently effective in shielding UV radiation. 

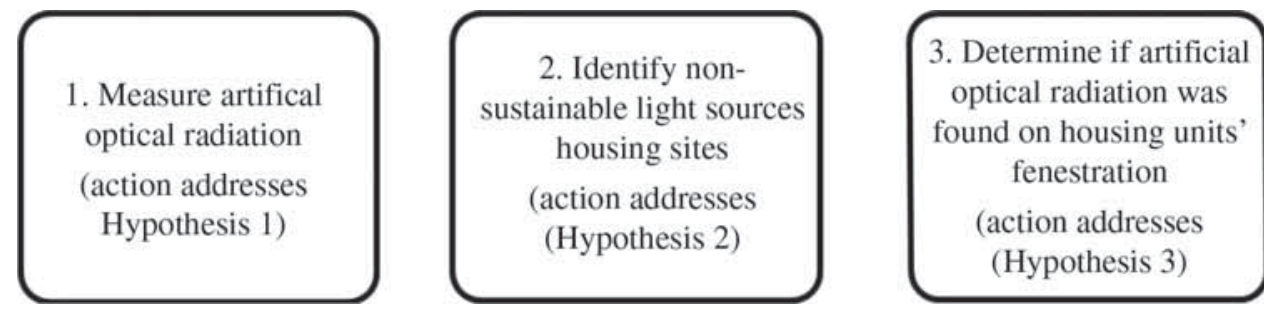

Figure 7: Linear diagram relating actions to hypotheses.

Lens maintenance will be important for continued UV mitigation. The main reason that researchers accepted Hypothesis 2 is that non-sustainable incandescent lights were the second most utilized light source, including overall. Incandescents are considered by many to be non-sustainable since they have low efficacy, are short-lived, and create the need for many bulbs to be relegated to landfills at their end-of-life due to barriers to recycling. Interestingly, no incandescents were found at the soldier sites. Possibly, the military's authoritative structure had allowed this entity to mandate uniform replacement or initial installation of more sustainable lighting sources throughout their facilities.

\subsection{Hypothesis 3: artificial VIS and IV radiation will be found on housing units' fenestration}

Researchers accepted Hypothesis 3 given data. The existing exterior lighting fixtures produced significant levels of vertical illumination on exterior walls of housing units in the current study. As a result, some light trespass was cast directly onto the windows of occupied student, soldier, and seniors rooms. These illuminance levels may disrupt circadian rhythms or contribute to other health problems for occupants. These are of concern, especially when one considers the vulnerability of some of the residents of these sites, college students and older adults. Stakeholders are encouraged to make informed choices regarding the selection, installation, and maintenance of sustainable lighting at housing sites.

\section{ACKNOWLEDGMENTS}

Although the research described in this paper has been funded wholly or in part by the United States Environmental Protection Agency through grant/cooperative agreement SU834732 to Oklahoma State University (OSU), it has not been subjected to the agency's required peer and policy review and therefore does not necessarily reflect the views of the agency and no official endorsement should be inferred.

The authors acknowledge the data collection contributions of the undergraduate and graduate OSU students enrolled in DHM 4573 Environmental Sustainability Issues for Interior Designers, and DHM Graduate Student, Sylvia Chaney, Professor Abimola Asojo and her students at the University of Oklahoma are also acknowledged for their data collection efforts. Also the authors wish to thank Delaina Goforth for her general assistance.

\section{REFERENCES}

[1] Hebert, P.R., "A Study of the Impacts of Existing Artificial Optical Radiation at Student Housing Sites.," in Sustainable Development and Planning V, eds. C.A. Brebbia \& E.Beriatos. WIT Press: Southampton, UK, pp. 249-259, 2011.

[2] Figueiro, M., Brainard, G.C., Lockley, S.W., Revell, V.L. \& White, R., Light and Human Health: An Overview of the Impact of Light on Visual, Circadian, Neuroendocrine, and Neurobehavioral Responses. Illuminating Engineering Society of North America: New York, NY, 2008. 
[3] Illuminating Engineering Society of North America (IESNA), Light and Human Health: An Overview of the Impact of Optical Radiation on Visual, Circadian, Neuroendocrine, and Neurobehavioral Responses. IESNA: New York, NY, 2008.

[4] Globe at Night. (n.d.). Less of Our Light for More Starlight, available at http://www. globeatnight.org/index.html

[5] Illuminating Engineering Society of North America (IESNA), Guideline for Security Lighting for People, Property and Public Spaces. IESNA: New York, NY, 2003.

[6] Winchip, S.M., Designing a Quality Lighting Environment, Fairchild Publications, Inc: New York, NY, 2005.

[7] Burgess, H.J., Sharkey, K.M. \& Eastman, C.I., "Bright light, dark and melatonin can promote circadian adaptation in night shift workers". Sleep Medicine Reviews, 6, pp. 407-420, 2002.

[8] Eastman, C.I., Stewart, K.T., Mahoney, M.P. \& Liu, L., "Dark goggles and bright light improve circadian rhythm adaptation to night-shift work". Sleep: Journal of Sleep Research \& Sleep Medicine, 17(6), pp. 535-543, 1994.

[9] Van Someren, E.J.W., Kessler, A., Mirmiran, M., \& Swaab, D.F., "Indirect bright light improves circadian rest-activity rhythm disturbances in demented patients". Biological Psychiatry, 41, pp. 955-963, 1997. doi: http://dx.doi.org/10.1016/S0006-3223(97)89928-3

[10] Yamadera, H., Ito, T., Suzuki, H., Asayama, K., Ito, R. \& Endo, S., "Effects of bright light on cognitive and sleep-wake (circadian) rhythm disturbances in alzheimer-type dementia". Psychiatry and Clinical Neurosciences, 54, pp. 352-353, 2000. doi: http://dx.doi.org/10.1046/ j.1440-1819.2000.00711.x

[11] Boyce, P.R., "Lemmings, Light, and Health”. Leukos, 2, pp. 175-184, 2006.

[12] Figueiro, M.G., Rea, M.S. \& Bullough, J.D., "Does architectural lighting contribute to breast cancer?". Journal of Carcinogenesis, 5, p. 20, 2006. doi: http://dx.doi.org/10.1186/1477-3163-5-20

[13] Rich, C. \& Longcore, T., (eds), Ecological Consequences of Artificial Night Lighting. Island Press: Washington, D.C, 2006.

[14] American Medical Association, "Resolution 516(a-09): Advocating and Support for Light Pollution Control Efforts and Glare Reduction for Both Public Safety and Energy Savings". American Medical Association, Chicago, IL2009.

[15] Swerdlow, A.J., English, J.S., MacKie, R.M., O’Doherty, C.J., Hunter, J.A., Clark, J. \& Hole, D.J., "Fluorescent lights, ultraviolet lamps, and risk of cutaneous melanoma". British Medical Journal, 297, pp. 647-650, 1988. doi: http://dx.doi.org/10.1136/bmj.297.6649.647

[16] Scientific Committee on Emerging and Newly-Identified Health Risks (SCENIHR). (2008). Light Sensitivity, available at http://ec.europa.eu/health/ph_risk/committees/04_scenihr/docs/ scenihr_o_019.pdf

[17] Ham Jr, W.T., "Ocular hazards of light sources: review of current knowledge". Journal of Occupational Medicine, 25, pp. 101-103, 1983.

[18] Kitchel, E. (n.d.). Light and Low Vision, available at http://cclvi.org/contributions/light_and_ low_vision.htm

[19] Kitchel, E. (2011). The Effects of Fluorescent Light on the Ocular Health of Persons with PreExisting Eye Pathologies, available at http://naasln.org/documents/articles/hudson_miller_02_ fluorescent_lighting_crisis.pdf

[20] U.S. Environmental Protection Agency (EPA). (2012). Health Effects of Overexposure to the Sun, available at http://www.epa.gov/sunwise/uvandhealth.html

[21] Rasmussen, T., Goepfrich, V. \& Horkitz, K. (2006). Drivers of Cfl Purchase Behavior and Satisfaction: What Makes a Consumer Buy and Keep Buying? available at http://www.cee1. org/eval/db_pdf/758.pdf 
[22] Bh 1, P., Zahnd, A., Eloholma, M. \& Halonen, L., "Replacing fuel based lighting with light emitting diodes in developing countries: energy and lighting in rural nepali homes". Leukos, 3, pp. 277-291, 2007.

[23] Kumar, A., Jain, S.K. \& Bansal, N., "Disseminating energy-efficient technologies: a case study of compact fluorescent lamps (Cfls) in India”. Energy Policy, 31, pp. 259-272, 2003. doi: http://dx.doi.org/10.1016/S0301-4215(02)00038-1

[24] Kjoerulf, F., "Transforming the Cfl market by consumer campaigns”. Right Light, KJÆRULF, 2, pp. 145-147, 1997.

[25] Peon, R., Doluweera, G., Platonova, I., Irvine-Halliday, D. \& Irvine-Halliday, G., "Solid-State Lighting for the Developing World-the Only Solution," in Optics and Photonics 2005, Proceedings of SPIE, 5941, ed, pp. 109-123, 2005.

[26] Reynolds, T.W., DeSisto, T.P., Murray, B. \& Kolodinsky, J., "Promoting energy efficiency in small island states: overcoming barriers to the adoption of compact fluorescent lighting in Saint Lucia”. International Journal of Consumer Studies, 31, pp. 460-467, 2007. doi: http:// dx.doi.org/10.1111/j.1470-6431.2007.00594.x

[27] Stall-Meadows, C. \& Hebert, P.R., "The sustainable consumer: an in situ study of residential lighting alternatives as influenced by infield education". International Journal of Consumer Studies, 35, pp. 164-170, 2011. doi: http://dx.doi.org/10.1111/j.1470-6431.2010.00987.x

[28] Freyssinier, J.P., Frering, D., Taylor, J., Narendran, N. \& Rizzo, P., "Reducing Lighting Energy Use in Retail Display Windows," in Sixth International Conference on Solid State Lighting Proceedings of SPIE 6337, 66371L, ed, 2006.

[29] Areni, C.S. \& Kim, D., “The influence of in-store lighting on consumers' examination of merchandise in a wine store". International Journal of Research in Marketing, 11, pp. 117-125, 1994. doi: http://dx.doi.org/10.1016/0167-8116(94)90023-X

[30] Hebert, P.R., "Title," unpublished.

[31] Atiles, J.H., Wysocki, J.L. \& Tremblay Jr, K.R., "Energy star: introducing a new cooperative extension partnership". Housing and Society, 30, pp. 59-68, 2003.

[32] Consortium For Energy Efficiency. (2010-2011). Cee's Residential Lighting Initiative, available at http://www.cee1.org/resid/rs-lt/rs-lt-main.php3

[33] Consortium For Energy Efficiency. (2007). Residential Lighting, available at http://www.cee1. org/resrc/facts/rs-lt-fx.pdf

[34] Arnstein, S.R., "A ladder of citizen participation". Journal of the American Institute of Planners, 35, pp. 216-224, 1969. doi: http://dx.doi.org/10.1080/01944366908977225

[35] Attardi, W., "Educating the General Public on Lighting a Good Idea?" Presented at the lluminating Engineering Society of North America Centennial Conference, New York, NY, 2006.

[36] Medicare. (n.d.). Glossary, available at http://www.medicare.gov/Glossary/m.html

[37] Centers for Medicare \& Medicaid Services, "Your Guide to Choosing a Nursing Home," ed. Washington, D.C.: U.S. Department of Health and Human Services, 2011.

[38] Rea, M., ed., The Iesna Lighting Handbook. Illuminating Engineering Society of North America: New York, NY, 2000.

[39] Walker, C., Bueter, C., Hurst, A., White, V. \& Patten, K. (n.d.). Globe at Night: Using Sky Quality Meters to Measure Sky Brightness, available at http://www.noao.edu/outreach/press/ pr08/files/GaN_SQM.pdf 